JOHNSON, B. M. Validation of a modified closed circuit, oxygen dilution residual volume method. MS in Adult Fitness/Cardiac Rehabilitation, 1993.41pp. (W. Floyd)

A modified closed circuit, oxygen dilution method for the measurement of residual volume (RV) was compared to the method described by wilmore (1969). The major difference in equipment was the substitution of a 7 liter calibration syringe and rubber rebreathing bag for the wet spirometer in the original procedure. Duplicate measurements of RV were made with each method in random order of 90 subjects (45 M, $45 \mathrm{~F}$ ) age 18 to 69 (mean $=31$ yrs). Test-retest

correlations were $r=.996$ for males and $r=.992$ for females with the modified method. For the pooled data ( $\mathrm{n}=$ 90) the correlation between the criterion method and the modified method was $r=.996$, with a mean difference of 3 mls between methods and a standard exror of prediction of 36 mls. The dead space in the modified method was $69 \mathrm{mls}$ whereas the spirometer method dead space was 1.140 liters. The modified RV method has less dead space, requires less costly components, provides a faster and less cumbersome procedure, and obviates the need to maintain a fixed water level in a spirometer for constancy of dead space. 


\title{
VALIDATION OF A MODIFIED CLOSED CIRCUIT, OXYGEN DILUTION RESIDUAL VOLUME METHOD
}

\author{
A THESIS PRESENTED \\ TO \\ THE GRADUATE FACULTY \\ UNIVERSITY OF WISCONSIN-LA CROSSE
}

IN PAR'TIAL FULFILLMENT

OF THE REQUIREMENTS FOR THE

MASTER OF SCIENCE DEGREE

BY

BRENDA M. JOHNSON

DECEMBER 1993 
COLLEGE OF HEALTH, PHYSICAL EDUCATION, AND RECREATION UNIVERSITY OF WISCONSIN-LA CROSSE

THESIS FINAL ORAL DEFENSE FORM

Candidate: Brenda M. Johnson

We recommend acceptance of this thesis in partial fulfillment of this candidate's requirements for a degree:

Master of Science in Adult Fitness/Cardiac Rehabilitation

The candidate has successfully completed her final oral examination.

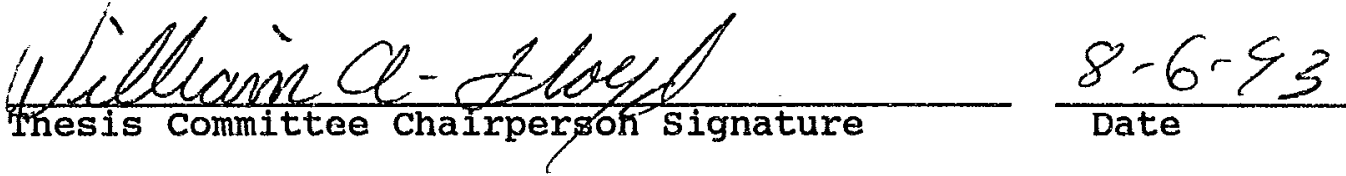

Denmia W. OBian

Thesis Committee Member Signature

$\frac{8.06 .93}{\text { Date }}$

Thes

Cpepten $C$. Vesch

Thesis tomittee Member signature

$\frac{8 / 10 / 23}{\text { Date }}$

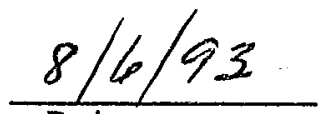

Date

This thesis is approved by the College of Health, Physical Education, and Recreation.

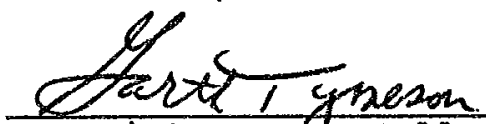

Associate Dealf college of Health, Physical Edyegtion, and Recreation
$12-6-93$

Date

11 Dec. 93

Deap of UW-L Graduate studies

Date 


\section{ACKNOWLEDGEMENTS}

I would like to acknowledge the following people:

Dr. William Floyd for this acceptance and support during the process of this thesis.

Mr. Jeffery Tesch for his time, patience, encouragement, and friendship from start to finish.

Dr. Dennis O'Brien for his support, enthusiasm, and taking time out for me when I had questions.

Dr. Philip K. Wilson for this direction and encouragement in the thesis process.

To all my classmates who were always supportive and understanding.

To': my good friends Peg and Diane, both of you had words of encouragement that meant the world to me.

To my parents who taught me the value of hard work yet were always concerned that I was working too hard. 
ACKNOWLEDGEMENTS

LIST OF TABLES......................... vi

IIST OF APPENDTCES.................... vii CHAPTER

I. INTRODUCTION ........................... 1

statement of the Problem............... 2

Need for the study..................... 2

purpose.......................... 2

Hypotheses......................... 3

Assumptions........................ 3

Limitations......................... 3

Delimitations....................... 4

Definition of Terms.................. 4

II. REVIEW OF RELATED LITERATURE............... 6

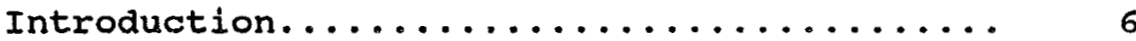

History of Residual Volume.............. 6

The Relationship of RV to Various

Physical Characteristics................ 10

RV and Age......................... 10

RV and Height..................... 11

RV and weight...................... 12

Summary........................... 12 
III. METHODS........................ 13

Introduction.................. 13

Measurement of Dead Space............. 13

Subject selection................ 13

Instruments used................. 14

Testing Procedures................. 15

Spirometer Method................. 16

Bag Method..................... 17

Recording $\mathrm{RV} . \ldots \ldots \ldots \ldots \ldots \ldots \ldots \ldots \ldots$

Statistical Analysis.............. 18

IV. RESULTS AND DISCUSSION.............. 20

Introduction.................... 20

Dead space........................ 20

Spirometer Dead space.............. 21

Bag Dead space.................. 24

subjects....................... 25

Reliability of the Measurements......... 25

RV Measurement.................. 27

v. ConcLustons...................... 32

summary ....................... 32

Conclusions...................... 33

Recommendation.................. 33

REFERENCES. . . . . . . . . . . . . . . . . . 35

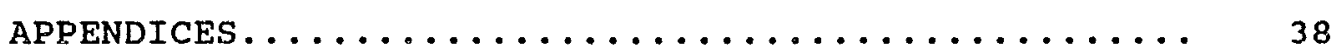




\section{LIST OF TABLES}

TABLE

PAGE

1. Correlation between physical

characteristics and Rv................. 11

2. Dead space calculations for spirometer method... 22

3. Characteristics of sample group........... 26

4. Pilot study means and standard deviations

of RV measurements................... 27

5. Means and standard deviations of

RV measurements.................... 28

6. RVs reported in present and prior studies...... 29

7. Correlation matrix of variables............ 30 


\section{LIST OF APPENDICES}

APPENDIX

PAGE

A. Infomed Consent Form.................... 39

B. Questionnaire/Data sheet..................4 41

vii. 
CHAPTER 1

\section{INTRODUCTION}

The residual lung volume (RV), defined as the amount of air remaining in the lungs after a maximal expiration, is not accessible to direct measurement (Boutellier \& Farhi, 1986). Measurement of RV is only accomplished through indirect measurement. The indirect methods most commonly used include (Christie, 1932): 1) the pneumatometric method, with use of the whole-body plethysmograph; 2) the closed circuit method, where there is dilution and eventual equilibration of an insert tracer or indicator gas such as helium, hydrogen, or nitrogen; and 3) the open circuit. method, where nitrogen is "washed out" of the lungs during a specified period of oxygen breathing.

The accuracy in measurement of $\mathrm{RV}$ is very important in the appraisal of pulmonary function and if this measurement is used along with the vital capacity and total lung capacity, one can evaluate the ability of the individual to provide alveolar aeration. The RV percent of total lung capacity is also a measurement used to quantify the severity of pulmonary emphysema. Residual volume has also been the most widely used lung volume in the hydrostatic weighing technique. According to Welch and Crisp (1958), since RV is the smallest lung volume it is the least affected by 
hydrostatic pressure and, therefore, the volume of choice.

\section{statement of the Problem}

The problem in this study was to determine if there is a significant difference in the RV calculated by a closed circuit spirometer method compared to a closed circuit bag method.

\section{Need for the study}

The use of a spirometer is common with closed circuit, oxygen dilution RV methods. The cost of a spirometer similar to the ore used in the current study is approximately $\$ 2,550$. The fact that the gas volume is contained over water can pose problems. For example, the water level must be consistently checked to maintain accurate dead spaces and the dead spaces are large and difficult to measure with accuracy. Since the dead space is large more time is required to reach equilibrium. For these reasons, a method to measure RV without a spirometer is needed.

\section{Purpose}

The purpose of this study was to compare RV obtained with a closed circuit, oxygen dilution spirometer method to RV obtained with a closed circuit, oxygen dilution bag method using a wide range of subjects. A reduction in the time and cost of RV measurement was expected with the bag method. In addition, the validity and reliability of both methods were to be tested. 


\section{Hypotheses}

The hypotheses of this study were stated in the null form.

1. There is no significant difference between RV measured by the spirometer method and the bag method.

2. There is no significant difference between repeated measures of $\mathrm{RV}$ by the bag method.

3. There is no significant difference between repeated measures of RV by the spirometer method.

4. There is no significant difference between RV measurements obtained by the first method tested and the second method tested (i.e., there is no ordering (effect).

\section{Assumptions}

The assumptions of this study were:

1. All subjects expired maximally in all RV trials.

2. All instruments functioned properly and provided accurate values.

3. All subjects were free of any respiratory impairment which would affect the accurate measurement of RV.

4. All subjects answered the questionnaire accurately.

\section{Limitations}

The limitations of this study were:

1. True randomization was not achieved, as all subjects were volunteers.

2. The trials for each RV method was limited to two. 
3. It was difficult to determine how well subjects performed the breathing maneuvers.

\section{Delimitations}

The delimitations of this study vere:

1. All subjects were volunteers from the La Crosse, wisconsin area.

2. All subjects were considered in good health.

3. All subjects were between the ages of 18 and 69 years.

\section{Definition of Terms}

The following terms were used in this study. Alveolar Nitrogen (AN) - percent nitrogen in the alveolar air at the beginning of the experiment (Wilmore, 1969). BTPS - body temperature (37 degrees $C$ ), ambient pressure, and $100 \%$ water saturation. Used for all gas measurements dealing with lung volumes (Fox, Bower, \& Foss, 1988). Closed Circuit, oxygen Dilution - rebreathing oxygen in a closed system to determine a lung volume (Wilmore, 1969). Dead Space - the volume of gas which cannot be emptied from the connecting apparatus of the RV system. Equilibrium Nitrogen (EN) - percent nitrogen in the spirometer or bag after equilibrium has been reached. Final Nitrogen (FN) - percent nitrogen in the lungs at the point of equilibrium.

Impurity Nitrogen (IN) - percent nitrogen in the spirometer or bag at the beginning of the procedure. 
open Circuit Method - a gas dilution technique in which nitrogen is washed out of the lungs and collected in a large spirometer by inhalation of pure oxygen through a sexies of one-way valves over a specific period of time.

Pack Years - the number of cigarette packs smoked per day multiplied by the number of years smoked.

Pneumatometric Method - a method of indirectly determining lung volumes through the use of whole body plethysmography (Wilmore, 1969).

Residual Volume - the volume of gas remaining in the lungs following a maximal exhalation (Boren, Kory, \& Syner, 1966). spirometer - an air-tight device consisting of two metal containers, one inverted over the other and sealed with water, capable of direct measures of lung volumes by the recording of inspirations and expixations on a rotating drum attached to a spirometer (Fox et al., 1988).

Smoking History - the total number of cigarettes smoked by the subject measured in pack years.

Volume Calibration syringe - an air-tight device consisting of a large aluminum cylinder with a movable pision that is attached to a calibrated rod with a handle. 
CHAPTER II

REVIEW OF RE'LATED LITERATURE

Introduction

The purpose of this study was to examine the relationship between $\mathrm{RV}$ determined by a spixometer method versus a bag method. It was also the purpose of this study to test the validity and reliability of the new bag method.

The proposed bag method differs from the established closed circuit, oxygen dilution spirometer method in several respects. First, the proposed method uses a less expensive volume calibration syringe and an inexpensive rebreathing bag that can be easily sterilized, whereas a more expensive spirometer is needed for the established reference method (Wilmore, 1969). The dead space is also greatly reduced and easier to measure with the bag method. Another advantage of the bag method is that the water level and humidity effects present with a water sealed spirometer are eliminated.

This chapter will discuss literature related to this study. The history of RV measurement and the relationship of RV to various physical characteristics will be discussed.

\section{History of Residual Volume}

The history of lung volume measurement dates back to the $1670^{\prime} \mathrm{s}$ when Borelli made an early effort to try to determine the volume of air in the lungs (Lundsgaard \& Vanslyke, 
1918). In 1788, Goodwyn reported in his own experiments that the lungs contain a considerable amount of air, even after complete expiration, and this quantity varied in subjects in proportion to the capacity of their thorax (Lundsgaard \& Vanslyke, 1918). It was $\operatorname{sir}$ Humphrey Davy, in 1800, who defined $\mathrm{RV}$ as the quantity of air remaining after a maximum expiration (Lundsgaard \& Vanslyke, 1918).

Throughout history a number of methods have been introduced for the indirect analysis of $\mathrm{RV}$ measurement. The methods today can be divided into the three groups proposed by Christie (1932) and wilmore (1969): 1) pneumatometric method, using scme form of plethysmograph, 2) closed circuit method, where there is dilution and eventual equilibration of an inert tracer or indicator gas such as helium, hydrogen or nitrogen, and 3) the open circuit method, where nitrogen is "washed out" of the lungs during a specified period of oxygen breathing.

Pfluger, in 1882, developed the pneumatometric method based on Boyle's Law, which states that the volume of gas varies inversely with the pressure to which it is subjected. An air-tight chamber connected to a spirometer is required for this method. The subject is able to breathe room air through a mouthpiece connected to an opening in the chamber. Inspiratory and expiratory processes cause air displacement inside the chamber, which is detected and then recorded on a spirometer. Expiration is then completely obstructed and 
the subject is instructed to make a maximal inspiratory or expiratory effort against this total resistance. The amount of air in the lungs is determined by measuring the change in pressure at the mouthpiece and the extent to which the thorax has expanded.

DuBois, Botelho, Bedell, Marsall, and Comroe, (1956) developed the technique of body plethysmography by applying more precise pressure measurements to Priluger's technique. There are a number of drawbacks to the pneumatometric method which requires a specialized chamber that has been described in the past to be very cumbersome and difficult to maintain (Christie, 1932).

Lundsgaard and Vanslyke (1918) described the method Goodwyn used in 1788 which was determined postmortem by filling the pleural cavity with water and compressing the lungs against a fixed diaphragm. Lundsgaard and Vanslyke (1918) described a closed circuit, oxygen dilution method to measure RV where the subject expired completely and then inspired from a bag or spirometer containing a known amount of nitrogen, oxygen, or hydrogen, which mixed with the air in the lungs when respired from five to seven times. Then the mixture was analyzed and the RV calculated from the degree to which the air in the chest had diluted the gas in the bag or spirometer.

Christie (1932) used hydrogen as an indicator gas in a closed circuit, oxygen dilution method. McMichael (1939) 
developed a variation of the hydrogen dilution method. This method was widely used until the hydrogen was replaced to avoid the dangers of explosion. Meneeley and Kaltreider (1949) used helium in a closed circuit with air to measure the RV.

In 1940, Darling, Cournand, and Richards described the open circuit nitrogen washout technique which was based upon the nearly complete removal of all the nitrogen from the lungs. Hickam and associates also used an open circuit, helium dilution method for measuring functional residual capacity (Motley, 1957). Weiner and Cooper reported that the closed circuit, helium dilution method, using air, is simpler; easier to perform, and more rapid than the method of helium diluted with oxygen (Motley, 1957).

wilmore (1969) modified the closed circuit, oxygen dilution method reported by Lundsgaard and Van slyke in 1918. The purpose of Wilmore's study was to provide a modified method to reduce the time necessary for a single determination of RV. Wilmore's modified method was validated against an open circujt method. The reproducibility of this method was established on a sample of 195 males with a test-retest correlation of .993 and a standard error of measurement of $28 \mathrm{ml}$, and on a sample of 102 females with a correlation of .987 and a standard error of measurement of $30 \mathrm{ml}$. Along with the high degree of validity and reproducibility the testing time for one 
subject was reduced to approximately 8 to 10 minutes instead of 15 to 30 minutes (Wilmore, 1969).

In 1980, wilmore, Vodak, Parr, Girandola, and Billing proposed a further simplified method for determining RV. This method eliminated the need for a nitrogen analyzer and a spirometer by using oxygen and carbon dioxide analyzers to determine the point of nitrogen equilibration and a 5-liter rebreathing bag to contain the oxygen. This simplified method reduced the total test time to 5 minutes or less. This method was found to be both reliable $(r=.99)$ and valid $(r=.92)$, with a standard error of prediction of 125 $\mathrm{ml}$, and a mean difference of only $8 \mathrm{ml}$, when compared with the established oxygen dilution technique.

The Relationship of RV to Various Physical Characteristics

Provided below is a review of literature pertaining to selected physical characteristics and their relationship to RV.

\section{RV and Age}

Brozek (1960) reported a gradual increase of RV with aging due to the reduced elastic recoil of the lungs and thorax. He went on to state that $R V$ values may be a tool in establishing the physiological age of an individual. Many other researchers have since investigated the effect age has on RV (Boren et al., 1966; Cox, 1989; Crapo, Morris, Clayton, and Nixon, 1982; Goldman \& Becklake, 1959; Grimby \& Soderholm, 1963; Koenig, 1990; Morrow, Van Handel, \& 
Bradley, 1989; Russell, 1987; Weidman, 1986). All concluded that RV increased with age. Table 1 includes a summary of the correlations between age and RVs reported by prior reseachers.

Table 1. Correlation between physical characteristics and RV

\begin{tabular}{lccc} 
Reference & Age & Height & Weight \\
\hline Boren et al. (1966) & .20 & .23 & .17 \\
Cox (1989)* & .59 & .40 & .33 \\
Crapo et al. (1982) & ++ & ++ & $* *$ \\
Goldman \& Becklake (1959) & .48 & .29 & .08 \\
Grimby \& Soderholm (1963) & ++ & ++ & ++ \\
Koenig (1990) + & .75 & .35 & .41 \\
Morrow et al. (1989) & ++ & ++ & ++ \\
Russell (1987) * & .66 & .31 & .21 \\
Weidman (1986) & ++ & ++ & $* *$
\end{tabular}

Note. +t positive correlation indicated but no data provided

* no correlation reported

+ data on male subjects only

* data on female subjects only

\section{and Height}

Goldman and Becklake (1959) found that RV correlated significantly with height $(r=.29, p<.01)$. Boren et al. (1966) found that each lung volume (i.e., RV and vital capacity) increased as height increased. Boren et al. 
(1966), also found a significant correlation between RV and height $(r=.23, p<.01)$. Additional research reporting similar findings are summarized in Table 1. RV and Weight

Compared to age and height, weight is less often used in prediction equations. Boren et al. (1966) reported weight was significantly correlated with $\mathrm{RV}$ in males $(r=.17, p=.01)$. Koenig $(1990)$ reported a correlation with greater significance for males $(r=.41)$ while cox (1989) and Russell (1987) also frund greater significance in correlations between weight and. $R V$ in females $(r=.33, r=$ .21 , respectively).

\section{Summary}

Several methods have been developed for the indirect measurement of $\mathrm{RV}$. Some methods are a modification of an earlier method and others use newly developed techniques. The literature suggests that the closed circuit, oxygen dilution method seems to be the fastest, and does not allow time for enough nitrogen from the blood to cross over into the alveoli to significantly alter the results. The literature also suggests that there is a relationship between selected physical characteristics and to RV. 


\section{CHAPTER III \\ METHODS \\ Introduction}

The methods and procedures used in this study are presented in the following sequence: measurement of dead space, subject selection, instruments used, testing procedures, and statistical treatment.

\section{Measurement of Dead Space}

Before the start of testing, the dead spaces were determined and measured in both methods. There are actually two dead spaces, one on the oxygen side and one on the subject side of the rebreathing valve. In both cases, the dead space volume was determined by measuring the volume of water that could be contained. The volumes were determined to the nearest milliliter using a graduated cylinder.

\section{Subject selection}

A total of 45 males and 45 females ranging from 18 to 69 years of age were subjects for this study. The subjects were volunteers from the La Crosse, Wisconsin area.

Upon entering the testing site each subject read and signed the Informed Consent Form (see Appendix A). All procedures were thoroughly explained and questions were answered. After the subjects signed the consent form they were given a questionnaire (see Appendix B) and instructed 
to answer all questions as honestly and accurately as possible.

Height and weight were determined with the subjects wearing street clothes without shoes.

\section{Instruments Used}

The following is a description of each instrument used during the test procedures:

Bag RV Method - A modified closed circuit, oxygen dilution method (Wilmore, 1969) was used to determine RV. The percent nitrogen in the system was determined using a nitrogen analyzer (Model 505D, Med Science, St. Louis, MO). A chart recorder (Model 585, Omega Engineering, stamford, CT) was connected to the analog output of the nitrogen analyzer to record nitrogen fractions. A 7-liter volume calibration syringe (Model 4900, Hans Rudoph Inc., Kansas City, MO) was used to measure the amount of oxygen, which was then transferred into a 7liter rubber bag for rebreathing. The amount of oxygen was usually between 4 and 6 liters. Questionnaire - A questionnaire was completed by each subject to give information concerning age, height, weight, smoking history, and cardiopulmonary history. Single-Beam Balance Scale - A mechanical platform scale (Model \#200 DLK, Health O-Meter Inc., Bridge View, IL) was used to weigh each subject to the nearest quarter pound. Spirometer RV Method - A closed circuit, oxygen dilution 
method (Wilmore, 1969) was used to measure RV. The percent nitrogen in the system was determined using a nitrogen analyzer (Model 505D, Med Science, st. Louis, MO). A chart recorder (Model 585, Omega Engineering, Stamford, CT) was connected to the analog output of the nitrogen analyzer to record nitrogen fractions. A 6-liter spirometer (Model p600 , พ.E. Collins Inc., Braintree, MA) was used to measure the amount of oxygen and also contained the oxygen during rebreathing. The amount of oxygen used was usually between 4 and 6 liters.

Stadiometer - A stadiometer (Accustat, Genentech, San Francisco, CA) was used for height determinations in inches:

Volume Calibration syringe - The 7-liter volume calibration syringe (Model \#4900, Hans Rudolph Inc., Kansas City, Mo) was used to measure oxygen and for calibration purposes.

\section{Testing Procedures}

Before testing either method the nitrogen analyzer was allowed to stabilize on room air and then the "adjust" knob was set to display 18.6, while sampling the calibration gas. The calibration gas was a mixture of oxygen and nitrogen. The oxygen content was determined by the method of Scholander (1947), and the nitrogen content was deternined by subtraction. The nitrogen analyzer was then allowed to sample room air a second time and the reading was recorded.

All tests were conducted with subjects in a sitting 
position and inclined slightly forward. Each subject's RV was measured by both methods in the same physical location and with the same body position.

The procedures were explained to the subjects while the systems were being flushed with oxygen for use. A mouthpiece marked with two lines was then set in place. One line was to show the point to which it should be inserted into the mouthpiece adapter and the other to show the subject where to position the lips around the mouthpiece. The procedures for the two methods vary slightly as explained below.

\section{Spirometer Method}

Before testing of each subject, the water level in the spirometer was checked and filled to a predetermined level to maintain a constant dead space. The spirometer circuit was flushed with oxygen three times using 4 to 5 liter volumes. The spirometer was emptied except for the constant dead space and the 2-way valve was turned to connect the mouthpiece to room air. A volume of oxygen was then put into the spirometer and measured by noting the pen position on the chart paper. At this time the subject was asked to put on a nose clip and seal the mouth around the mouthpiece. The subject was then instructed to take a full inhalation and exhale maximally. After exhaling to the fullest possible extent the subject raised an index finger to signal the researcher. At this point the researcher connected the 
subject to the oxygen-filled spirometer and instructed the subject to breathe in and out rapidly and deeply until a nitrogen equilibrium was reached between the lungs and the spirometer.

\section{Bag Method}

The bag circuit was flushed two times using 4 to 5 liters of oxygen. During the second flush, the two-way valve connecting the mouthpiece was opened to allow oxygen to fill the cut out in the valve plug. This volume was included in the oxygen dead space. An arbitrary amount of oxygen was then put into the bag. In order to establish the same conditions, oxygen was humidified by bubbling it through a water bottle before it passed into the rebreathing bag. A volume calibration syringe was used to draw the oxygen out of the bag so it could be measured. After the measurement was recorded the oxygen was pumped back into the bag. A pneumatic switch inflated a balloon valve to close the bottom of the bag. At this point the subject put on the nose clip and sealed the mouth around the mouthpiece. The subject was then instructed to take a full inhalation and exhale maximally. After exhaling to the fullest possible extent the subject raised an index finger to signal the researcher. At this point the researcher connected the subject to the oxygen-filled bag and instructed the subject to breathe in and out rapidly and deeply until a nitrogen equilibrium was reached between the lungs and the bag. 
Recording RV

If the two trials for either method differed by more than $50 \mathrm{ml}$ a third and sometimes fourth trial was administered. The chart recorder tracing was examined to determine $A N, I N, E N$, and $F N$ which were entered into the computer to calculate the RV. The following formula, a slight modification of the abbreviations used by Wilmore (1969) was used to calculate RV:

$$
\mathrm{RV}=(\mathrm{BTPS} \text { correction) } \mathrm{x}[\mathrm{BV} \times(\mathrm{EN}-\mathrm{IN}) /(\mathrm{AN}-\mathrm{FN})-\mathrm{DS}]
$$

Where: BTPS = Body temperature ( 37 degrees $C)$, ambient pressure, and $100 \%$ water saturation. Used for all gas measurements dealing with lung

$$
\begin{aligned}
& \quad \text { volumes (Fox et al. 1988). } \\
& \text { BV = Bag Volume } \\
& \text { EN = Equilibrium Nitrogen } \\
& \text { IN }=\text { Impurity Nitrogen } \\
& \text { AN }=\text { Alveolar Nitrogen } \\
& \text { FN }=\text { Final Nitrogen } \\
& \text { DS = Dead Space }
\end{aligned}
$$

\section{Statistical Analysis}

Statistical analysis was performed using ABSTAT software (Release 5.09, Anderson-Bell, Arvada, CO). Paired t-tests were used to evaluate the significance of differences between the bag method and the spirometer method. A Pearson product moment correlation was used to determine the test- 
retest reliability coefficients of the two methods.

The standard error of prediction as decribed by wilmore, Vodak, Parr, Girandola and Billing, (1980) was used with the following equation:

standard Error of Prediction $=\sqrt{\text { Sy } 1-r^{2}}$

Where: $\quad S y=$ standard deviation of the mean of RV values as measured by the proposed method (i.e., the modified method).

$\mathbf{r}=$ Pearson product moment correlation between method 1 and method 2 . 
CHAPTER IV

\section{RESULTS AND DISCUSSION}

\section{Introduction}

The purpose of this study was to determine if there was a significant difference between the RV measured by the bag method and the RV measured by the spirometer method. The proposed bag method differs from the established closed circuit spirometer method in several respects. First, the proposed bag method uses a less expensive volume calibration syringe and an inexpensive rebreathing bag that can be easily sterilized, whereas a more expensive spirometer is employed in the originally published oxygen dilution method. The dead space is smaller and more easily measured with the bag method. Another advantage of the bag method is that the water level maintenance required with a water sealed spirometer is eliminated.

This chapter includes the results of the dead space measurements, subjects characteristics, and the statistical analysis of the collected data.

\section{Dead Space}

Where possible dead space was determined by measuring the volume of water that the space contained to the nearest milliliter. Dead space was also calculated by dilution from 
the mathematical equation when possible. The dead spaces were calculated for the oxygen side and the subject side of both methods.

\section{Spirometer Dead Space}

on the oxygen side of the spirometer system the dead space consisted of four parts. The average of three measurements was used for each part:

1) The average water volume contained in the curved dome of the spirometer bell was $132 \mathrm{ml}$ by water containment.

2) The average water contained in the vertical spirometer tube and the horizontal connecting tube leading to the respiratory valve was $485 \mathrm{ml}$.

3) : The vertical tube of the spirometer had a radius of $1.75 \mathrm{~cm}$. This tube projected up $3.5 \mathrm{~cm}$ into the dome of the bell. The volume contained by this section of tubing (to be deducted from the total), was calculated as follows:

$$
(3.14)(1.75 \mathrm{~cm})^{2}(3.5 \mathrm{~cm})=34 \mathrm{~cm}^{3}=34 \mathrm{ml}
$$

4) When the spirometer was filled with water to a previously established line a constant air space extended $2.54 \mathrm{~cm}$ below the curved dome at the top edge of the spirometer bell (radius $=8 \mathrm{~cm}$ ). The following equation was used to determine the amount of dead space enclosed:

$$
(3.14)(8 \mathrm{~cm})^{2}(2.54 \mathrm{~cm})=510 \mathrm{~cm}^{3}=510 \mathrm{ml}
$$

The total dead space in the spirometer was equal to 1.093 liters:

$132 \mathrm{ml}+485 \mathrm{ml}-34 \mathrm{ml}+510 \mathrm{ml}=1093 \mathrm{ml}$ 
The dead space was also determined by dilution giving an average $(n=12)$ of 1.140 liters which was used in testing as shown in Table 2 .

Table 2. Dead space calculations for spirometer method

\begin{tabular}{ccccccc}
\hline $\begin{array}{l}\text { Syringe } \\
\text { Setting }\end{array}$ & $\begin{array}{l}\text { Syringe } \\
\text { Volume }\end{array}$ & AN & IN & EN & FN & $\begin{array}{c}\text { Dead Space } \\
\text { Calculation }\end{array}$ \\
\hline 1.0 & 3.10 & 77.9 & .7 & 19.6 & 19.6 & 1.178 \\
1.0 & 3.55 & 77.9 & .6 & 18.2 & 18.2 & 1.155 \\
1.0 & 4.70 & 77.9 & .7 & 15.4 & 15.4 & 1.197 \\
1.0 & 4.82 & 76.9 & .6 & 15.1 & 15.1 & 1.091 \\
1.5 & 5.31 & 76.8 & .7 & 17.9 & 17.9 & 1.152 \\
1.5 & 3.83 & 76.8 & .4 & 21.5 & 21.5 & 1.116 \\
1.5 & 4.90 & 76.7 & .5 & 18.7 & 18.7 & 1.114 \\
1.5 & 4.96 & 76.9 & .6 & 18.7 & 18.7 & 1.108 \\
2.0 & 5.00 & 76.9 & .6 & 22.0 & 22.0 & 1.124 \\
2.0 & 5.60 & 76.8 & .7 & 20.6 & 20.6 & 1.141 \\
2.0 & 4.04 & 76.8 & .6 & 24.6 & 24.6 & 1.152 \\
2.0 & 3.50 & 76.8 & .7 & 26.5 & 26.5 & 1.153 \\
\hline
\end{tabular}

The following equation was used to determine unknown spirometer volumes by dilution:

$$
\text { SVDS }=\operatorname{PVDS}(A N-F N) /(E N-I N)
$$

where: PVDS = Pump Volume Dead Space

$\mathrm{AN}=\mathrm{Alveolar} \mathrm{Nitrogen}$ 


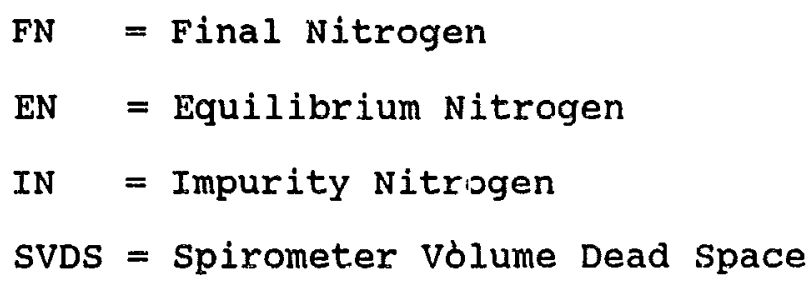

The dead space on the pump side of the spirometer system was determined by measuring the volume of water that the space could contain. The measurements consisted of four parts. The average of three measurements was used for each part:

1) The average water volume contained in the cutout of the repiratory valve on the handle side of the plug was 13 ml.

2) The average water volume contained between the plug and screw-in port of the respiratory valve was $2 \mathrm{ml}$.

3) The average water volume contained inside the two connecting ports ( 1.375 inch O.D.) plus the plug cutrout and the connecting port ( 1.375 inch O.D.) on the other sicie was $82 \mathrm{ml}$.

4) The average water volume contained inside the mouthpiece and rubber adapter was $45 \mathrm{ml}$.

The total dead space on the oxygen side of the spirometer system was $142 \mathrm{ml}$ :

$13 \mathrm{ml}+2 \mathrm{ml}+82 \mathrm{ml}+45 \mathrm{ml}=142 \mathrm{ml}$

When calibrating with the volume calibration syringe the 
mouthpiece and adapter were removed thus reducing the dead space by $45 \mathrm{ml}$. The syringe dead space of $290 \mathrm{ml}$ was also added giving a total of $387 \mathrm{ml}$ of dead space on the syringe side for calibration:

$$
142 \mathrm{ml}-45 \mathrm{ml}+290 \mathrm{ml}=387 \mathrm{ml}
$$

\section{Baq Dead Space}

The dead space in the bag system was determined by measuring the volume of water contained to the nearest milliliter. The dead space on the oxygon side consisted of three parts with the average of three measurements taken for each part:

1) The average water volume contained in the right angle cut through the value plug in the repiratory valve was $11 \mathrm{ml}$.

2) The average water volume contained between the plug and screw-in port of the respiratory valve was $2 \mathrm{ml}$.

3) The average water volume contained in the $22 \mathrm{~mm}$ port and the neck of the rebreathing bag (with a thumb pushing the bag against the port) was $18 \mathrm{ml}$.

The total dead space on the oxygen side of the bag system was $31 \mathrm{ml}$ :

$$
11 \mathrm{ml}+2 \mathrm{ml}+18 \mathrm{ml}=31 \mathrm{ml}
$$

The dead space on the subject side of the bag system was determined using the same procedures. The subject side dead space consisted of two parts. The average of three 
measurements was used for each part:

1) The average water volume contained in the $22 \mathrm{~mm}$ port, the adapter, and the mouthpiece was $67 \mathrm{ml}$.

2) The average water volume contained between the plug and screw-in port of the respiratory valve was $2 \mathrm{ml}$.

The total subject side dead space for the bag system was $69 \mathrm{ml}:$

$$
67 \mathrm{ml}+2 \mathrm{ml}=69 \mathrm{ml}
$$

\section{Subjects}

The subjects involved in this study consisted of 45 females and 45 males from 18 to 69 years. The subjects were volunteers from the La crosse, wisconsin area. The subject characteristics of age, height, and weight are summarized in Table 3 .

In this study the male subjects were similar in height, weight and age to subjects in two other studies (Boren, et al. 1966; Koenig, 1990). The female subjects in this study were also similar in characteristics to those in three other studies (Cox, 1989; Marshall, 1957; Whitfield, Arnott, \& Waterhouse, 1951).

\section{Reliability of the Measurements}

A pilot study was conducted prior to actual data collection to establish the reliability of the measures. A total of 4 males and 4 females between 18-51 years were subjects for this particular study. Measurements of RV were 
obtained from both methods. A Pearson product moment correlation coefficient was used to determine the testretest reliability coefficients of the two methods. The reliability coefficient of the bag method was .997 and the spirometer system was .996. These high correlations indicated that the measurements were reliable.

\section{Table 3. Characteristics of sample group}

Variable

Mean

S.D.

S.E. of Mean

Age (yr)

$\begin{array}{llrl}\text { All }(n=90) & 30.6 & 11.5 & 1.2 \\ \text { Female }(n=45 ; & 29.4 & 8.9 & 1.3 \\ \text { Male }(n=45) & 31.8 & 13.6 & 2.0\end{array}$

Height (cm)
All
174.5
20.3
1.1
Female
167.1
7.9
1.2
Male
181.9
6.4
0.9

Weight $(\mathrm{kg})$
A11
75.4
11.9
1.2
Female
67.2
9.7
1.4
Male
83.6
7.1
1.1

The results of the pilot study are presented in Table 4 . The t-statistic of -1.019 indicated no statistically 
significant difference between the means. A t-statistic of \pm 2.365 was necessary for significance at the .05 level.

Table 4. Pilot study means and standard deviations of RV measurements

Variable

Mean

$S D$

Spiro RV 1

1.629

.421

Spiro RV 2

1.615

.429

Spiro Mean

1.622

.425

Bag RV 1

1.614

.398

Bag RV 2

1.630

.381

Bag Mean

1.622

.389

RV Meaǹ

1.626

.402

Note. $n=8$

$\mathrm{RV}$ mean is the mean of spiro mean and bag mean

\section{RV Measurement}

The means and standard deviations of the bag RV method and the spirometer RV method trials for all 90 subjects are reported in Table 5 .

The RVs measured by the closed circuit, oxygen dilution spirometer method resulted in a mean of 1.626 liters. The RVs measured by the closed circuit oxygen-dilution bag method resulted in a mean of 1.623 liters. Therefore, the difference between the mean values of duplicate measurements by each method was only 3 milliters. 
Table 5. Means and standard deviations of RV measurements

$$
\text { All }(n=90) \text { Males }(n=45) \text { Females }(n=45)
$$

\begin{tabular}{llll}
\hline Spiro RV 1 & $1.629 \pm .387$ & $1.804 \pm .359$ & $1.453 \pm .332$ \\
Spiro RV 2 & $1.624 \pm .381$ & $1.797 \pm .335$ & $1.450 \pm .326$ \\
Sprio Mean & $1.626 \pm .383$ & $1.801 \pm .356$ & $1.452 \pm .329$ \\
Bag RV 1 & $1.623 \pm .386$ & $1.798 \pm .366$ & $1.448 \pm .325$ \\
Bag RV 2 & $1.623 \pm .381$ & $1.795 \pm .361$ & $1.451 \pm .322$ \\
Bag Mean & $1.623 \pm .384$ & $1.797 \pm .363$ & $1.449 \pm .323$ \\
RV Mean & $1.625 \pm .382$ & $1798 \pm .358$ & $1.451 \pm .325$ \\
\hline
\end{tabular}

Note. All values are mean \pm standard deviation.

The RVs reported in the present study are in close agreement with the values reported in other studies, as shown in Table 6 .

When each independent variable was analyzed singularly, with the male and female data pooled, age showed the highest correlation to $\mathrm{RV}$ as in previous studies (Boren et al. 1966; Cox, 1989; Goldman \& Becklake, 1959; Koenig, 1990; Russell, 1987). The correlation of RV with age in the present study is higher than studies have shown in the past (Boren et al. 1966; Goldman \& Becklake, 1959) studies with females only done by Cox (1989) and Russell (1987), and a study on males only done by Koenig (1990). 
Table 6. RVs reported in present and prior studies

\begin{tabular}{lcccc} 
Reference & Sex & N & Mean RV & Mean Age \\
\hline Boren et al. (1966) & M & 134 & 1.71 & 37 \\
Goldman \& Becklake (1959) & M & 44 & 2.04 & 44 \\
Johnson (1993) & M & 45 & 1.80 & 32 \\
Koenig (1990) & M & 100 & 1.50 & 33 \\
Whitfeild, Arnott, \& & & & & 39 \\
$\quad$ Waterhouse (1951) & M & 58 & 1.75 & 38 \\
Goldman \& Becklake (1959) & F & 50 & 1.55 & 29 \\
Johnson (1993) & F & 45 & 1.45 & 38 \\
Whitfeild, Arnott, \& & & & & 1.41 \\
$\quad$ Waterhouse (1951) & F & 31 & & 39 \\
\hline
\end{tabular}

The correlation coefficients for the independent variables of age, height, and weight are presented in Table 7.

When the independent variables were analyzed by gender, age was shown to have a much higher correlation with RV in males than females as reported in Table 5. A correlation of .925 between age and RV for males is higher than any reported in the literature (Boren et al. 1966; Goldman \& Becklake, 1959; Koenig, 1990). The correlation of .763 between age and RV for females is only slightly higher than the .660 correlation found by Russell (1987) and .590 found by $\operatorname{cox}(1989)$. The correlation for males of -.054 found 
between height and RV was not in agreement with previous studies as seen on Table 1 .

Table 7. Correlation matrix of variables

\begin{tabular}{|c|c|c|c|c|}
\hline & $\mathrm{RV}$ & Age & Height & Weight \\
\hline \multicolumn{5}{|c|}{ A11 $(N=90)$} \\
\hline RV & 1.000 & & & \\
\hline Age & .804 & 1.000 & & \\
\hline Height & .456 & -.053 & 1.000 & \\
\hline Weight & .537 & .139 & .782 & 1.000 \\
\hline \multicolumn{5}{|c|}{ Males $(n=45)$} \\
\hline RV & 1.000 & & & \\
\hline Age & .925 & 1.000 & & \\
\hline Height & -.054 & -.367 & 1.000 & \\
\hline Weight & .207 & .021 & .546 & 1.000 \\
\hline \multicolumn{5}{|c|}{ Females $(n=45)$} \\
\hline $\mathrm{RV}$ & 1.000 & & & \\
\hline Age & .763 & 1.000 & & \\
\hline Height & .439 & .005 & 1.000 & \\
\hline Weight & .464 & .180 & .569 & 1.000 \\
\hline
\end{tabular}

In order to determine any statistically significant difference between the bag method and the spirometer method, a dependent $t$-test was performed. The .05 level of significance was selected. The t-statistic of 
-.797 indicated no statistically significant difference between the bag mean and the spirometer mean. A t-statistic of \pm 2.365 was necessary for significance at the .05 level. An intercorrelation coefficient of $r=.996$ indicated that the degree of common variance of individual mean values for the two methods was extremely high. 


\section{CHAPTER V \\ CONCLUSIONS}

\section{Summary}

The purposes of this study were to propose a modification of an existing method of obtaining RV which reduced the cost of the system and the amount of dead space. In addition, an attempt was made to establish the validity and reliability of the method which resulted from this modification. Residual volume was calculated via both methods and paired t-tests were used to determine the significance at the .05 level.

A high test-retest correlation between duplicate trials of the bag method $(r=.996)$ and the spirometer method $(x=.996)$ suggested that reliable measures were taken with each method.

There were no statistically significant differences between the means of the bag and spirometer method as indicated by a dependent t-test.

The bag method was found to have many advantages over the spirometer method through the course of this study. The calculation of dead space was simplified and substantially reduced with the bag method as compared to the spirometer method. The problem of water level and humidity was 
elevated with the bag method. The cost of the RV system was substantially reduced with the bag system.

\section{Conclusions}

The following conclusions resulted from this study:

1. There was no significant difference between RV measured by the bag method as compared to that measured by the spirometer method. The null hypothesis was accepted.

2. There was no significant difference between repeated measures of RV measured by the bag method. The null hypothesis was accepted.

3. There was no significant difference between repeated measures of RV measured by the spirometer method. The null hypothesis was accepted.

4. There was no significant difference between RV measurements obtained by the first method tested and the second method tested (i.e., there was no ordering effect). The null hypothesis was accepted.

\section{Recommendations}

The following are recommendations for future studies:

1. Use the data from this study in various prediction equations.

2. Set up the same study using a larger group of subjects with a wider age spread. 
3. Set up the new bag method to be used with human subjects immersed in water for hydrostatic weighing purposes.

4. Set up the new bag method without the spirometer method sharing connections to test the reliability of the bag method alone. 


\section{REF ERENCES}

Boren, H.G., Kory, R.C., \& Syner, J.C. (1966). The veterans administration-army cooperative study of pulmonary function: II. The lung and its subdivisions in normal men. The American Journal of Medicine, 41, 96-114.

Boutellier, U., \& Farhi, L.E. (1986). A fundamental problem in determining functional residual capacity or residual volume. Journal of Applied Physiology, 60 (5), 1810-1813.

Brozek, J. (1960). Age differences in residual lung volume and vital capacity of normal individuals. Journal of Gerontology, 15, 155-160.

Christie, R.V. (1932). The lung volume and its subdivisions. Journal of Clinical Investigation, 11, 1099-1118.

Cox, K. (1989). A formula developed for the prediction of residual volume of female subjects while immersed. Unpublished master's thesis, University of Wisconsin-La Crosse, La Crosse, WI.

Crapo, R.O., Morris, A.H., Clayton, P.D., \& Nixon, C. (1982). Lung volumes in healthy nonsmoking adults. Bulletin of European Physiopathology of Respiration, 18, 419-425.

Darling, R.C., Cournand, A., \& Richards, D.W. (1940). studies on the intrapulmonary mixture of gases: III. An open circuit method for measuring residual air. Journal of Clinical Investigations, 19, 609-618.

DuBois, A., Botelho, S., Bedell, G.N., Marsall, R., \& Comroe, J.H. (1956). A rapid plethysmographic method for measuring thoracic gas volume. A comparison with nitrogen washout. method for measuring functional residual capacity in normal subjects. Journal of clinical Investigations, 35. $320-329$.

Fox, E.L., Bowers, R.W., \& Foss, M.L. (1988). The physiological basis of physical education and athletics (4th ed.). Philadelphia: Saunders. 
Goldman, H.I., \& Becklake, M.R. (1959). Respiratory function tests: Normal values at median altitudes and the prediction of normal results. American Review of Tuberculosis and Pulmonary Disease, 79, 457-467.

Grimby, G., \& Soderholm, B. (1963). Spirometric studies in normal subjects: III. Static lung volumes and maximum voluntary ventilation in adults with a note on physical fitness. Acta Medica Scandinavica, 173, 199-206.

Koenig, J. (1990). A formula developed for the prediction of functional residual capacity and residual volume of male subjects while imniersed. Unpublished master's thesis, University of Wisconsin-La Crosse, La Crosse, WI.

Lundsgaard, C., \& Vanslyke, D.D. (1918). Studies of lung volume I. Relation between thorax size and lung volume in normal adults. Journal of Experimental Medicine, 27, 6585.

Marshall, R. (1957). The physical properties of the lungs in relation to the subdivisions of lung volumes. Clinical Science, 16, 507-515.

McMichael, J. (1939). A rapid method for determining lung capacity. Clinical Science, 4, 167-173.

Meneeley, G.R., \& Kaltreider, N.L. (1949). The volume of the lung determined by helium dilution. Journal of Clinical Investigations, 28, 129-139.

Motley, H.L. (1957). Comparison of a simple helium closed with the oxygen open-circuit method for measuring residual air. American Review of Tuberculosis and Pulmonary Disease, 76, 601-615.

Morrow, J.R., Van Handel, P.J., \& Bradley, P.W. (1989). Development of valid pulmonary function equations for trained athletes. International Journal of Sports Medicine, 10(1), 43-47.

Russell, D. (1987). A new formula for the prediction of residual volume in females. Unpublished master's thesis, University of Wisconsin-La Crosse, La Crosse, WI.

Scholander, P.F. (1947). Analyzer for accurate estimation of respiratory gases in one-half cubic centimeter samples. Journal of Biological Chemistry, 167, 235-250. 
Weidman, D. (1986). A new formula for the prediction of residual volume. Unpublished master's thesis, University of Wisconsin-La Crosse, La Crosse, WI.

Welch, B.E., \& Crisp, C.E. (1958). Effect of the level of expiration on body density measurement. Journal of Applied physiology, 12(3), 399-402.

Whitfield, A.G.W., Arnott, W.M., \& Waterhouse, J.A.H. (1951). The effects of tabacco on lung volume. Quarterly Journal of Medicine, 20, 138-143.

Wilmore, J.H. (1969). A simplified method for determination of residual lung volumes. Journal of Applied Physiology, 27(1), 96-100.

Wilmore, J.H., Vodak, P.A., Parr, R.B., Girandola, R.N., \& Billing, J.E. (1980). Further simplificaiton of a method for determination of residual lung volume. Medicine and Science in Sports and Exercise, 12(3), 216-218. 
APPENDIX A

INFORMED CONSENT FORM 
INFORMED CONSENT

FOR THE VALIDATION OF A. RESIDUAL VOLUME METHOD

I,

have agreed to volunteer to participate in a study to validate a modified oxygen dilution residual volume system. My participation in this study involves breathing into an apparatus to determine the amount of air remaining in my lungs after a maximal exhalation. My height and weight will be measured and I will also complete a questionnaire regarding cardiac and respiratory disorders, age, and smoking history prior to the testing. The actual testing session will consist of obtaining four residual volume measurements, two with a spirometer system and two with a bag system (testing sequence will be randomly assigned). The time for the total test will be 15 minutes.

The possible risks that may occur in this study are dizziness, nausea, possible electrocardiographic (EKG) changes due to forced expiration. Instruments will be disinfected and cleaned prior to testing, but the possibility of infection always exists.

I have read the above information, and I have been fully advised of the nature of the procedure and what is expected of a participant in this study. I an aware of the possible risks involved and that I may withdraw form this study at any time.

In signing this consent form, I hereby release the University of Wisconsin-La Crosse, the La Crosse Exercise and Health Program, the Human Performance Laboratory employees and students engaged in my evaluation process form any and all legal liability associated with the above described procedures. The testing will be conducted by Brenda Johnson, a graduate student in Adult Fitness and cardiac Rehabilitation, under supervision of william Floyd, Ph.D.

To my knowledge, I am not limited by any condition(s) that would affect my ability to participate in this study.

Signed

Date

Witness

Date 


\section{APPENDIX B}

\section{QUESTIONNAIRE/DATA SHEET}


Residual Volume Data Sheet

water level

nose clip

room air

Name

Date

Phone number

Age

Height

inches

Weight pounds

1. Do you suffer from any respiratory disorders such as asthma, bronchitis, or tuberculosis? YES NO

2. Have you ever had heart surgery of any kind or suffered a heart attack? YES No

3. Do you or have you ever smoked? YES NO If yes, how many packs per day do/did you smoke? If yes, how many hears have/had you smoked?

4. Do you suffer from any other condition(s) that the investigator should be aware of? If so, please explain:

Spirometer system---order of test 1st

Initial Vol. oxygen of itrogen Alveolar \&Nitrogen Impurity \&Nitrogen Equilibrium \&Nitrogen Final

RV

\section{Baq System}

Initial vol. oxygen sitrogen Alveolar onitrogen Impurity sNitrogen Equilibrium \&Nitrogen Final

RV Trial 1

2nd

Trial 2
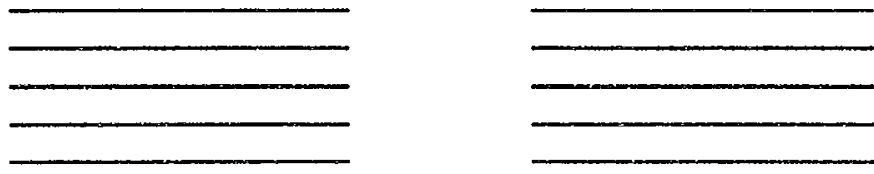

Trial 1

Trial 2 